\title{
Animal Cancer Model
}

National Cancer Institute

\section{Source}

National Cancer Institute. Animal Cancer Model. NCI Thesaurus. Code C41162.

An animal model which develops cancer or can be used to generate a model that develops cancer. 